\section{Have We Solved Darwin's Dilemma?}

\author{
Massimo Pigliucci
}

THE PLAUSIBILITY OF LIFE: Resolving Darwin's Dilemma. Marc W. Kirschner and John C. Gerhart. xvi +314 pp. Yale University Press, 2005. \$30.

$\mathrm{I}$ s life plausible? Well, it's more than What we need to ask, rather, is whether our explanations for how life came about and diversified are plausible. So the title of Marc W. Kirschner and John C. Gerhart's book implies the wrong question. Despite that, The Plausibility of Life makes for informative and enjoyable reading, and the issues the authors raise are worthy of attention.

The book takes as its starting point the position that the currently accepted version of evolutionary theory, the so-called Modern Synthesis, although not wrong, is incomplete. Similar rumors have been circulated in other recent books,

including Mary Jane West-Eberhard's Developmental Plasticity and Evolution, Eva Jablonka and Marion Lamb's Evolution in Four Dimensions, and Phenotypic Evolution, a book by Carl Schlichting and myself. But those rumors have been strenuously denied by researchers who have situated their careers squarely within the Synthesis, which came of age in the 1930s and 1940s.

The two key questions concerning The Plausibility of Life, then, are, Do we actually need to add more components to the structure of evolutionary theory? And if so, is Kirschner and Gerhart's book the contribution some of us have sought for years? The answer to the first question is plausible, it has actually happened!

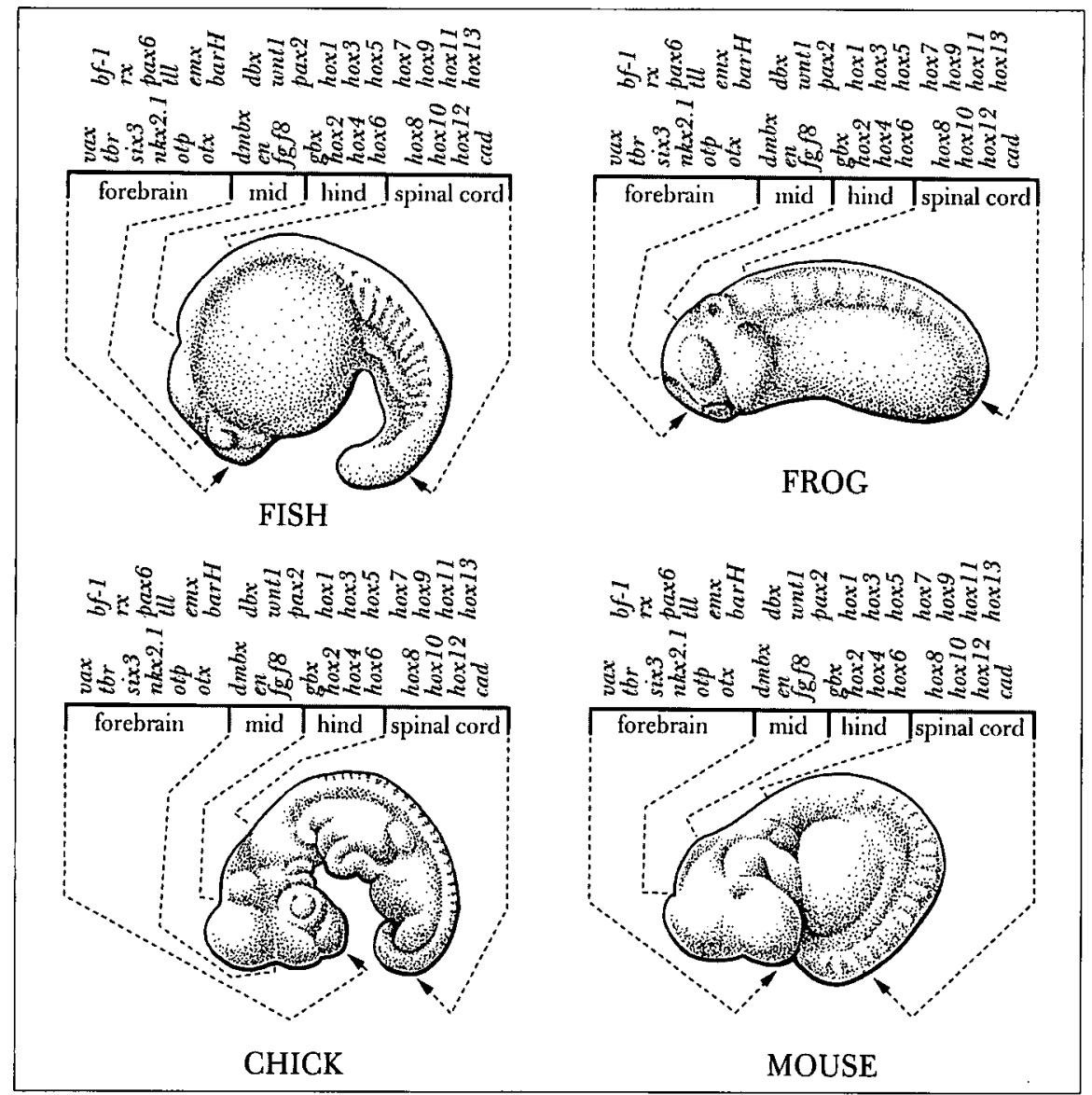

Ernst Haeckel has been accused of overstating in his 1874 drawings the anatomical similarities between various vertebrate embryos. Nevertheless, the four phylotypic-stage embryos shown here do have obvious anatomic similarities, despite their different shapes. In addition, they have the same map of compartments of selector-gene expression, as the gene names above the drawings indicate. From The Plausibility of Life. a definite "yes," and to the second one, a qualified "partially so." Let me explain.

The Modern Synthesis itself built on Darwin's two major realizations: first, that all living organisms are related to one another by common descent; second, that a primary explanation for the pattern of diversity of life-and especially for the obvious "fit" of organisms to their environments-is the process that he called natural selection. It took about seven decades for biologists to add the next round of important building blocks to the Darwinian view of life. Modern Synthesists such as Theodosius Dobzhansky, Ernst Mayr, George Gaylord Simpson and G. Ledyard Stebbins reconciled disparate fields of biology, from population genetics to paleontology, by expanding the array of evolutionary processes to include migration, mutations, assortative (nonrandom) mating and (random) genetic drift.

What the Modern Synthesis glaringly left out was the field of developmental biology and its subdiscipline, embryology, which wandered almost on their own for a few additional decades, until "evo-devo" (evolutionary developmental biology) came into vogue in the 1990s. The incompleteness of the Synthesis consisted not only in leaving out that entire area of research (which would be bad enough) but also in failing to address (or worse, sweeping under the carpet) important questions, chief among them the problem of the origin of so-called evolutionary novelties.

Evolutionary novelties are those (usually) complex structures that allow the organisms that evolve them to exploit new aspects of their environment or to adapt to new niches, often in a spectacularly successful fashion. They also happen to be the sort of thing Darwin struggled with most in On the Origin of Species: eyes, wings, hearts and brains. Not coincidentally, the difficulty of evolving such complex biological structures has also fueled evolution deniers, from the Reverend William Paley (whose "watch found on the heath" argument evoked an extensive response from Darwin) to the modern supporters of so-called "intelligent design."

Now, it has never been clear to me why the existence of natural phenomena that are at the moment difficult to explain seems to fuel both the reaction that "there is a fundamental flaw in the theory" (intelligent design) and the opposite response that "there is nothing wrong, everything has been explained" (the Modern Synthesis). Science, by its 
very nature, deals with things for which we lack explanations-things that might otherwise compel us to turn to supernatural notions. By the same token, if evolutionary biologists really had already explained everything, what on earth would justify my job as an active researcher?

Assuming, then, that there really are problems that have not been satisfactorily solved within the Modern Synthesis, do Kirschner and Gerhart provide us with answers? Well, first of all, the book is aimed at a general audience. Thus it is hard to evaluate it as an original contribution to science, because many of the arguments are not sufficiently developed or are not substantiated by a thorough analysis of the literature. This is an interesting trend that seems to have taken hold in recent years (Evolution in Four Dimensions is another example), and it is hard to know what to make of it. On the one hand, we are witnessing a welcome return to the idea that cutting-edge science is for everybody. Darwin's On the Origin of Species, after all, sold out on its first day and was purchased by laypeople as well as academics (of which there were few at the time anyway). On the other hand, with trade books one can get away with speculations and generalizations that would be harder to pass through the rigorous process of peer review that technical books usually undergo.

Be that as it may, Kirschner and Gerhart's main idea is that the missing piece in the edifice of the Modern Synthesis is what they call "facilitated variation." The basic idea is sound: Organisms are not analogous to human-engineered machines (contrary to what creationists and proponents of intelligent design keep insisting); rather, they are characterized by developmental systems that are capable of accommodating quite a bit of disruption-be that from changes in the external environment (phenotypic plasticity) or from mutations in their genetic makeup (genetic homeostasis). This ability to accommodate is in turn made possible by the modular structure of the genetic-developmental system itself, which allows organisms to evolve new phenotypes by rearranging existing components. A splendid example of this evolutionary and developmental flexibility is provided by the homeobox genes that preside over the spatial differentiation of embryos, from fruit flies to humans.

Facilitated variation is indeed one of the empirical as well as conceptual developments that have marked evolu- tionary biology during the past decade or so. However, it is not the stunningly new insight that Kirschner and Gerhart imply it to be. Plenty of other authors have talked about concepts such as the modularity of organisms, genetic and developmental homeostasis, evolution by alteration of regulatory sequences, and even evolution as a continuous process of "tinkering" with preexisting elements (as opposed to creating new complex characters from scratch)-an idea put forth by François Jacob as long ago as 1977. Kirschner and Gerhart's effort is a valuable update of some of these ideas, but it hardly constitutes "a new theory" to complement the Modern Synthesis.

Kirschner and Gerhart also peculiarly ignore or downplay at least two other major pieces of the evolutionary puzzle that have been brought forth recently as crucial to the development of a new synthesis. One is the inherent capacity of organisms to accommodate phenotypic plasticity - environmentally or genetically induced changes. Plasticity has been studied for more than a century, but it has come of age in the past two decades as a central characteristic of living organisms, one that has been implicated in speciation, adaptation and the origin of

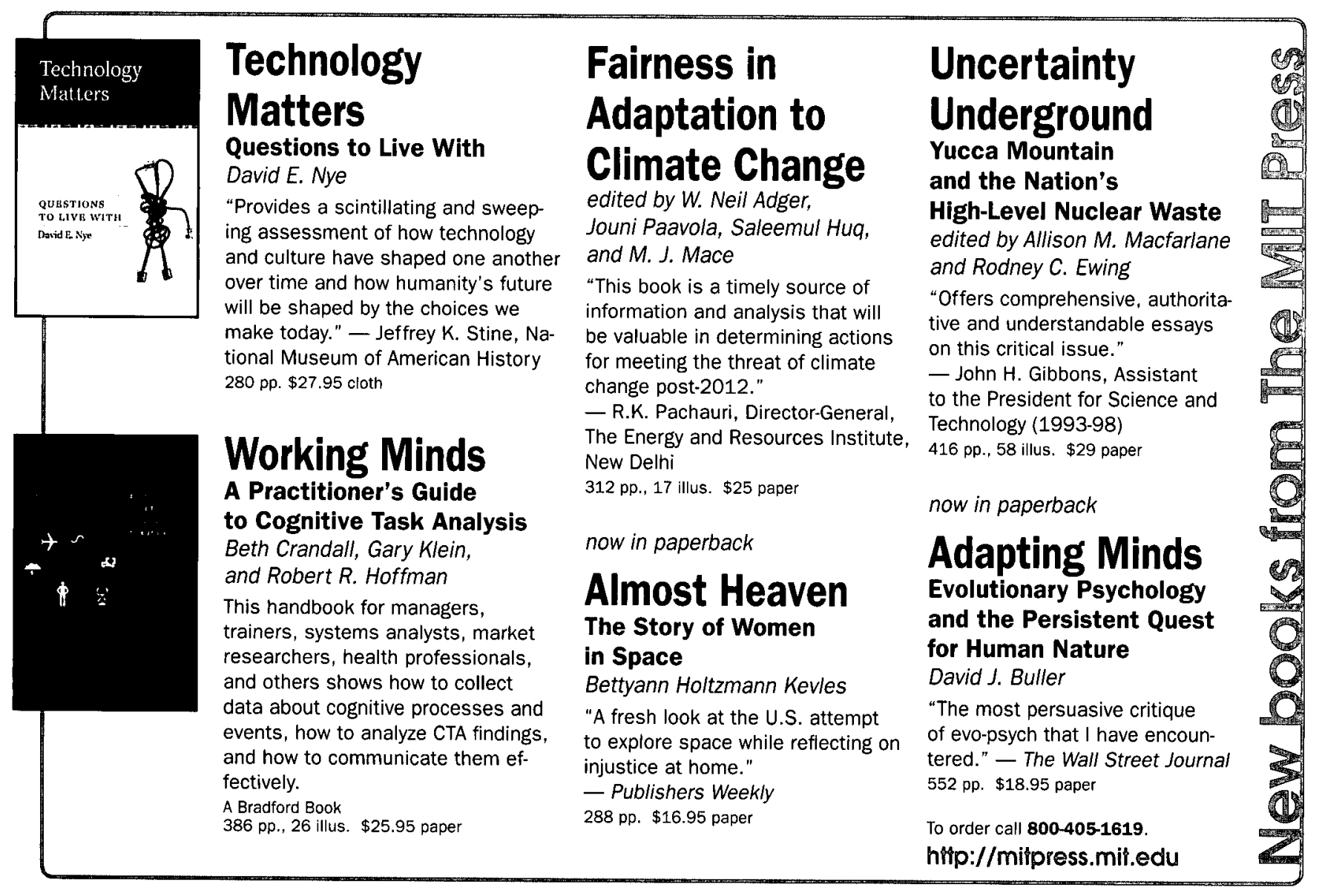


phenotypic novelties. Although Kirschner and Gerhart do mention phenotypic plasticity, they confine it to a secondary role (the term doesn't even make it into the index). They apparently do not realize that it is a crucial component of what they call facilitated variation.

The second crucial piece, entirely missing from The Plausibility of Life, is the (very) recent resurgence of the concept of inherited epigenetic variation. A significant amount of empirical research and at least one book tackling its conceptual implications (Evolution in Four Dimensions) are forcing biologists to face the existence of several layers of heritable variation above and beyond the classical genetic one. Inherited epigenetic variants can interact with their genetic counterparts to multiply by orders of magnitude the phenotypic variation available to natural selection, thereby expanding the mechanistic bases of evolutionary theoretical explanations and greatly increasing their plausibility as an account of life's diversity.

The Plausibility of Life ends with a brief critique of intelligent design, suggesting that the concept of facilitated variation will provide a solid argument to rebut creationists. I applaud the authors' intention, as it seems to me that more scientists ought to face the realities of public misunderstanding of science. But their presentation is too brief, and a bit too simplistic. The "controversy" about evolution has nothing to do with the soundness of scientific explanations of the history of life: It's not a scientific controversy, but a social, cultural and political one. Creationism is the result of centuries of antiintellectualism in the United States, coupled with sometimes cynical exploitation of the issue for political gain. In addition, many scientists have no interest in getting out of the ivory tower to talk to the very same public that pays their salaries and funds their precious research grants. The recent defeat of intelligent design at the trial in Dover, Pennsylvania-at the hand of a conservative judge appointed by George W. Bush-will do much mone to promote sanity in public education than any theory about facilitated variation, as scientifically sound as the latter may be.

Massimo Pigliucci is an associate professor in the department of ecology and ecolution and in the philosoply department at Stony Brook University. He is the author of several books, including Denying Evolution: Creation, Scientism, and the Nature of Science (Sinauer, 2002) and Phenotypic Plasticity: Beyond Nature and Nurture (Jolms Hopkins University Press, 2001). wuvw.genotypebyenvironment.org

\section{HISTORY}

\section{A Visionary and a Scoundrel}

\section{Rosalind Reid}

THE COMMERCIAL AND POLITICAL ATLAS AND STATISTICAL BREVIARY. William Playfair. Edited and introduced by Howard Wainer and lan Spence. Cambridge University Press, 2005. \$39.99.

A nyone who has clicked the popular button that commands a spreadsheet computer program to make a chart has experienced the satisfaction of seeing a confusing grid of numbers resolve into crisp bars. It is hard now to imagine how we ever got by without visual tools for understanding masses of data. But of course such devices as the bar graph, the time-series line graph and the pie chart had to be invented. The peculiar man who came up with all three was William Playfair (1759-1823), a Scot who was convinced he could influence Britain's course with visual explanations of macroeconomic trends. Endowed with drafting experience and confident in the power of graphical language, he presented his polemics in a new form: annotated graphs that vividly highlighted trade gaps and the growing national debt.

Although Edward Tufte (author of The Visual Display of Quantitative Information [1983]) and others have noted Playfair's role as the leading originator of modern statistical graphics, access to his work has heretofore been limited. Finally Playfair can speak for himself: Facsimiles of two of his most important works-the 1801 edition of The Commercial and Political Atlas, and The Statistical Breviary of the same year-have now been published in one small, affordable volume.

The vision that emerges from Playfair's pages is one of startling clarity and foresight. Even those who have seen samples of his charts-perhaps in Tufte's 1983 book or in statistician Howard Wainer's 2005 volume, Graphic Discovery: A Trout in the Milk and Other Visual Adventures-will find new treasures here, all in color and some on foldout pages. The facsimiles are prefaced by a lively introduction in which the editors-Wainer and psychologist Ian Spence-give us a glimpse of the work's creator and his times.

Born in a village near Dundee, William was the younger brother of John Playfair, who became a distinguished mathematician, physicist and geologist.
After learning drafting in the employ of the engineer-inventors Andrew Meikle and James Watt, William sought his fortune in London. Failing at the first of several doomed business ventures, he turned to writing about economics. The Commercial and Political Atlas-a series of 44 graphs charting selected trends in England's trade and national finances, each followed by remarks and observations-appeared in a preliminary edition circulated privately in 1785 .

Playfair's Atlas was a historical singularity. Graphs and charts did not, as one might have assumed, coevolve with science, business and government. Rather, the new medium emerged full-blown in Playfair's works (although other graphic forms did crop up in isolated experiments around the same time). And then, just as quickly, it vanished.

Graphic explanation simply did not catch on. Excellently constructed by today's standards, Playfair's charts were in his own day neither praised nor imitated. He eagerly sent copies to well-placed acquaintances, yet most took no interest. One of the few exceptions was the French king Louis XVI, who understood immediately that the charts "spoke all languages."

Another century or so would pass before the emerging field of statistics grasped the power and utility of graphical presentation. Wainer and Spence attribute the slow adoption of statistical charts to the intellectual climate of Playfair's Britain, where empiricism was ascendant. The empiricists, who argued that knowledge arises from sensory experience, recorded observations and plotted them on line graphs in their notebooks. But they valued rigor and precision, and pictures created to represent observations were necessarily less accurate and more interpretive than were numbers themselves. A "general mistrust of pictorial representation" in British science continued into the early 19th century (and a cautious skepticism about graphic presentation of data remains part of scientific culture today). 